Vol. 7, No. 1.

ISSN: 1473-8376

www.heacademy.ac.uk/johlste

ACADEMIC PAPER

\title{
Incorporating Problem-Based Learning Strategies to Develop Learner Autonomy and Employability Skills in Sports Science Undergraduates
}

\author{
Louise Martin (I.martin@worc.ac.uk), Julia West (j.west@worc.ac.uk) \\ and Karen Bill (k.bill@worc.ac.uk) \\ School of Sport and Exercise Science, University of Worcester, \\ Henwick Grove, Worcester, WR2 6AJ, UK
}

DOI:10.3794/johlste.71.169

@Journal of Hospitality, Leisure, Sport and Tourism Education

\begin{abstract}
This study investigated the impact of a 12-week problem-based learning (PBL) intervention on three psychological constructs (motivation, locus of control and self-esteem) linked to learner autonomy. Results indicated that there was a significant increase in the students' intrinsic motivation $(P<0.05)$ and a non-significant shift towards an internal locus of control after the intervention period. Students perceived the benefits of PBL to be the opportunity to work in teams and to consider a wider knowledge base. A short course of PBL was successful in developing learner autonomy and other key employability skills alongside the application of content knowledge.
\end{abstract}

Keywords: Academic motivation; Locus of control; Self-esteem

\section{Introduction}

During problem-based learning (PBL), knowledge is developed by studying problems or real life scenarios in a relevant context. However, the traditional learning order is reversed, with the problem being presented first and acting as a stimulus for learning, rather than the problem being presented after the dissemination of relevant theory by the tutor (Chin and Chia, 2004; Morrison, 2004). Students work in groups to solve problems and take responsibility for their own learning through a process of encountering a problem and exploring resources to provide an acceptable, justified solution (Mennin et al., 2003). Students are required to work cooperatively while acting as both learners and teachers

Louise Martin is a senior lecturer in sports science at the University of Worcester and a university teaching fellow. She has received HEA HLST subject funding for two pedagogical research projects and is interested in developing problem-based learning and e-learning. She is a practising BASES accredited sport and exercise physiologist (scientific support) and a laboratory director supporting a range of endurance athletes.

Julia West is a senior lecturer in sport and exercise science at the University of Worcester. She has an interest in sport and exercise psychology and has worked with a range of athletes and sports. Her main focus is on motivation and self-confidence and the effects these have on performance.

Karen Bill is a principal lecturer in enterprise and external relations in the School of Sport and Exercise Science, and a knowledge transfer fellow at the University of Worcester. She is author of a number of HEA HLST subject centre publications/resources related to enterprise and employability and is project manager for a number of employability initiatives. Her main teaching and research interests are sports law and sports entrepreneurship. She is currently embarking on the International Entrepreneurship Educators Programme. 
(Mennin et al., 2003; Mierson and Freiert, 2004). Consequently, PBL is embedded in constructivist theory as students construct their own knowledge, making meaningful cognitive, social and experiential connections between prior knowledge, experiences and newly acquired knowledge (Cross, 1999).

PBL has been widely used, with great success, in a range of vocational curricula, notably medicine and law. While typically there is no significant difference in academic achievement between PBL and traditional students (Albanese and Mitchell, 1993; White et al., 2004), research indicates that students develop an improved attitude towards learning and higher level thinking skills when PBL is used - for example, critical analysis, problem solving and reflection (Heliker, 1994). Spronken-Smith (2005) reported that students perceived greater development of problem-solving and analytical skills following a PBL module in research methods. Duncan and Al-Nakeeb (2006) and Duncan et al. (2007) found that students perceived themselves to have improved critical thinking skills, autonomy and employmentrelated skills following both short and longer PBL courses in sports science. There is also evidence to suggest that students perceive that they have a greater ownership of their own learning when following a PBL curriculum (Cockrell et al., 2000; Duncan and Al-Nakeeb, 2006). Learning behaviours have also been reported to change with PBL approaches, with students demonstrating increased motivation, wider reading and critical thinking skills (Duncan and Al-Nakeeb, 2006). PBL is not without its difficulties, however. Students frequently report frustrations in managing and coping with group dynamics (Dahlgren and Dahlgren, 2002; Miller and Peterson, 2003; Spronken-Smith, 2005) as well as managing the increased workload and time demands that PBL can generate (Spronken-Smith, 2005; Yeung et al., 2003).

Competent sport and exercise science practitioners require problem identification and resolution skills, effective communication skills and the ability to apply content theory to practice in a variety of situations in order to realise the performance potential of a client. Consequently, sport and exercise science undergraduates need to develop their autonomy, independence and employability skills through learning.

Learner autonomy has been linked to a number of psychological constructs, particularly motivation, locus of control and self-esteem (Fazey and Fazey, 2001). Motivation initiates the pursuit of an activity and can be further divided into two major concepts: intrinsic and extrinsic. While some extrinsic motivation is desirable, many additional benefits are gained from a high level of intrinsic motivation (Vansteenkiste et al., 2006). When a learner becomes autonomous, she or he accepts responsibility for decisions concerning all aspects of learning (Clifford, 1999). Locus of control (LOC) reflects an individual's explanation for achievement or failure in any given task or performance measure. Individuals who accept personal responsibility for an outcome demonstrate an internal LOC, whereas those who seek to apportion blame elsewhere exhibit an external locus of control (Chan, 2001a, 2001b; Zimmerman, 2000). Self-esteem is a more stable, enduring construct and allows the individual to feel valued. Thomas and Gadbois (2007) indicate that self-esteem refers to global evaluations of oneself. Self-esteem exists in a hierarchical framework, so overall global self-esteem is affected by many facets. Murphy and Roopchand (2003) illustrate this in an academic setting by explaining that students with high self-esteem focus on their strengths in other aspects of their lives to suppress negative thoughts associated with failure. Conversely, individuals with low self-esteem are more accepting of negative feedback and this impacts on future motivation.

Literature supports the idea that the process of PBL results in an increase in intrinsic motivation (Dolmans et al., 1997) and is likely to lead towards a shift in internal LOC (Pierson, 1996). Self-esteem may impact on the extent to which an individual engages in the PBL process, influencing in particular an individual's ability to make a meaningful contribution to their group's exploration of the problem(s) presented. Students who judge their capability to accomplish tasks to be low will demonstrate lower levels of autonomy than those students who believe they have a high capability to carry out the same tasks (Pajares and Valiante, 2002; Seifert, 2004; Zimmerman, 2000). The degree of learner autonomy perceived by an individual will therefore be dependent on the integration of motivation, LOC and self-esteem. 
Chaput de Saintonge and Dunn (1998) measured changes in self-efficacy and attribution style of medical students before and after an eight-week course designed to develop student autonomy. On completion of the course there had been a significant shift in attribution style from external causes to self-responsibility. There are clear links between the central learning processes of PBL and learner autonomy because students are required to construct their own learning framework (Mennin et al., 2003; Mierson and Freiert, 2004; Chung and Chow, 2004; Kremer-Hayon and Tillema, 1999; Zimmerman, 2000; Pajares and Valiante, 2002; Chan, 2001a). However, the degree of autonomy demonstrated for any individual also relies on their prior learning experience, attitude and knowledge of learning (Dickinson, 1987).

A variety of terms are used to describe students' ability to process and apply information appropriately which are assumed to be synonymous in relation to the wider skills agenda (Holmes, 2001). It is these flexible skills which are most prized by employers, and the assumption is that they are developed within a graduate programme (Glover et al., 2002). It may not be the skills per se which employers seek from graduates; it is more the flexible nature of these skills and the ability to use appropriate combinations across a variety of situations (Little, 2001). Miliszewska and Tan (2004) advocate the provision of a final and allencompassing module within a degree programme whereby students can synthesise and consolidate knowledge while integrating experiential learning, real-world problem solving, teamworking, decision making, critical thinking and interpersonal communication. A variety of anecdotal evidence strongly suggests that PBL is an ideal medium for developing some of these employability skills and approaches, yet this has not been empirically studied.

Dochy et al. (2003) and Newman (2003) reviewed existing literature to identify the effects of PBL. While Newman (2003) maintained that very few articles included controlled quantitative data to demonstrate the effectiveness of PBL, Dochy et al. (2003) identified 43 studies that met the robust inclusion criteria of their meta-analysis of PBL. They reported that, in the medical sciences, PBL had a moderate but practically significant effect on skills (application of knowledge) and a small but non-significant effect on knowledge (Dochy et al., 2003). It appears, therefore, that there is still a need for studies which investigate the learner benefits of PBL using a controlled research design to add to the existing body of knowledge, particularly in subjects outside the medical sciences.

The aims of the present study were twofold. The principal aim was to examine the impact of a 12-week PBL programme on learner autonomy (motivation, LOC, self-esteem). The study also aimed to investigate student perceptions regarding opportunities to develop employability skills through a PBL approach.

\section{Method and research design}

This project utilised a 'within groups design', testing assumptions and perceptions both before and after the PBL intervention process. Both qualitative and quantitative measures were used to collect data relating to perceptions of PBL and learner autonomy.

\section{Ethical considerations}

The University Ethics Committee approved the study prior to participants giving their informed consent. Focus group sessions were timetabled so as not to clash with the mandatory lecture times, and attendance at these non-compulsory sessions was regarded as participant assent.

\section{Participants}

The 25 participants were all in their final year of a sport and exercise science degree. The majority of students were classified as traditional entry students, with 8 per cent of the class classified as 'mature' students on entry to the degree programme. The module - Sport and Exercise Science in Practice - was designed to provide students with an opportunity to develop their knowledge in the subject disciplines of physiology, psychology, biomechanics and nutrition in a multidisciplinary format and then apply this knowledge scientifically to a 
Martin, West and Bill (2008) Incorporating Problem-Based Learning Strategies to Develop Learner Autonomy and Employability Skills in Sports Science Undergraduates

series of contemporary, real-life scenarios. A PBL approach to teaching was deemed most appropriate to address the module's aims and learning outcomes.

\section{Research measures}

Three scales were used to ascertain motivation, self-esteem and locus of control. These scales were similar to those used by Fazey and Fazey (2001), and previous research indicated that these were the areas where PBL and learner autonomy shared some common ground (Kremer-Hayon and Tillema, 1999; Zimmerman, 2000; Pajares and Valiante, 2002; Chan, 2001a).

1) The academic motivation scale (AMS-C 28; Vallerand et al., 1992) is based on the hierarchical model of motivation and assesses intrinsic motivation (subdivided into: 'to know'; 'toward accomplishment'; and 'to experience stimulation'), extrinsic motivation (subdivided into: 'identified'; 'introjected'; and 'external regulation') and amotivation. The questions include 'Why do you go to university?' and the responses are scored on a Likert scale from 1 to 7 ( 1 = does not correspond at all; $7=$ corresponds exactly). It has been shown that the three types of intrinsic motivation are significantly and positively correlated with each other $0.67,0.62$ and 0.58 , while the three types of extrinsic motivation are significantly and positively intercorrelated $0.50,0.49$ and $0.45(P<0.05)($ Cokley, 2000).

2) Rosenberg's self-esteem scale (Rosenberg, 1989) measures a global concept of selfesteem and consists of 10 items scored on a Likert scale ( 1 = strongly disagree; $4=$ strongly agree). Scores can range from 10 to 40 points. Test-retest correlations range from 0.82 to 0.88 and Cronbach's alpha ranges from 0.77 to 0.88 .

3) The academic locus of control scale (Trice, 1985) measures the degree to which an individual has either an internal or external locus of control. Participants circle 'true' or 'false' against a number of statements relating to themselves or their situation. The scoring awards a point for every correct match so, by disagreeing with a false statement (ie selecting 'true'), the participant scores 0 for that question. Test-retest reliability was 0.92 while internal consistency was 0.70 (Daum and Wiebe, 2003). Participants who take responsibility for their learning and achievements and demonstrate an intrinsic desire to learn have an internal locus of control in the range of 0 to 14; and the lower their score, the higher their internal locus of control. Conversely, participants who score 14 to 28 have an external locus of control (Trice, 1985).

\section{Procedure}

Participants were asked individually to complete the three measures at the beginning and on completion of the 12-week PBL intervention. On each occasion participants were interviewed in four random groups. Focus groups were chosen to supplement the quantitative data because they provide a means of capturing a richness of information on individuals' perceptions and are a useful tool to look back retrospectively on an experience of an intervention (Morgan and Krueger, 1998). The focus groups were administered according to Patton (2002) and followed a predetermined semi-structured format whereby broad questions were posited to elicit student perceptions of PBL, learner autonomy and traditional didactic learning methods, which were derived from literature searches. At the beginning of each focus group, researchers discussed how each participant's confidentiality and anonymity would be protected, and how they needed to respect the confidentiality and anonymity of the group and each group member. All focus groups were audiotaped and subsequently transcribed in order to identify primary and secondary hierarchical themes.

On completion of baseline data, participants were divided into four PBL groups of seven students, and the 12-week intervention was undertaken. While the initial allocation to groups was randomised, some minor amendments were made subsequently to ensure that membership was different from the focus groups. This aimed to provide some objectivity regarding evaluation of the process and also to help optimise group composition. For the initial three weeks each group undertook a series of skills training sessions which were designed to promote knowledge of PBL, to develop group interaction and cooperation, and to 
equip students with advanced research skills. Students also participated in a demonstration PBL session led by an experienced PBL tutor from the institution.

The intervention phase then continued for a further nine weeks. This was implemented as three separate scenarios which were each facilitated and researched over three weeks. Scenarios were all presented in text and picture format and outlined the situation of a current sports personality (Appendix). They required students to provide a programme of multidisciplinary sports science support to facilitate maintenance/improvement of performance of the profiled athlete. The PBL format used was based on the seven-jump process as used at the University of Maastrict, which was aligned with a format previously reported (O'Neil, 2003). A full PBL model was utilised throughout the intervention, which meant that there was no direct dissemination of content theory or input of possible solutions. The tutor served as a facilitator, encouraging students to explore their ideas in an academic framework and to encourage them to consider all potential solutions as fully as possible. This approach was adopted in preference to a hybrid model that incorporates lectures and other tutor-disseminated content to ensure that the learning environment was as different as possible from traditional didactic learning styles. At the end of every timetabled session each week, all groups completed a report sheet where they listed the learning objectives that had been identified and the investigative tasks of each individual for that week. At the end of the third and final week for each scenario, all groups were required to share their findings and support programmes with the other groups. Tutor feedback was provided following the completion of each scenario.

\section{Data analysis}

Quantitative data from the academic motivation self-esteem scale and locus of control scale were each tested for normal distribution using Levene's test of equality and error variables. All data were found to be significant - that is, not normally distributed $(P<0.05)$ - therefore pre- to post-intervention comparisons were analysed using the Wilcoxon signed ranks test and a significance level of $P<0.05$ was set.

Qualitative data were analysed to identify key themes associated with the research aims using margin coding (Bertrand et al., 1992). Preliminary thematic coding framework was organised into initial and then higher codes. An iterative process of constant comparison and analytic induction (Strauss and Corbin, 1990) was used to support or modify the emerging themes until further re-reads reached a final distillation of themes. Quotes from the focus groups were then selected on the grounds of representativeness.

Quotes in this paper have been coded by the prefix 'pre' or 'post' to represent before or after the PBL intervention, and a suffix G1, G2, G3 or G4 to identify which focus group the student belonged to.

\section{Results}

\section{Quantitative data}

The results showed a significant change $(z=-3.049, P=0.002)$ in the intrinsic motivation 'to know' subscale of the AMS-C 28. The remaining subscales did not show significance $(P>0.05)$, although there was an emerging trend. For example, the intrinsic motivation (IM) scores all increased while most of the extrinsic (EM) scores decreased, which suggests a more intrinsic focus. The academic locus of control data indicated a non-significant shift towards an internal focus, although the scores still remained relatively high $(z=0.163$, $\mathrm{P}=0.871$ ). Self-esteem data increased from pre- to post-intervention, although not to a significant level $(z=-1.449, P=0.147)$. 
Martin, West and Bill (2008) Incorporating Problem-Based Learning Strategies to Develop Learner Autonomy and Employability Skills in Sports Science Undergraduates

\begin{tabular}{lcccc}
\hline \hline Category & Pre-test data & Post-test data & $\begin{array}{c}\text { Z scores pre- } \\
\text { to post- }\end{array}$ & P values \\
\hline \hline IM to know & 15.300 & $18.600^{*}$ & -3.049 & .002 \\
IM to accomplish & 14.800 & 15.900 & -.699 & .484 \\
IM to experience stimulation & 12.600 & 13.300 & -.782 & .434 \\
EM identification & 21.700 & 21.700 & -.000 & 1.000 \\
EM introjection & 19.000 & 18.300 & -.505 & .614 \\
EM eternal regulation & 21.000 & 20.300 & -.652 & .515 \\
AM & 6.200 & 6.600 & -.153 & .879 \\
Academic locus of control & 14.600 & 12.800 & -.163 & .871 \\
Self-esteem scale & 29.700 & 32.300 & -1.449 & .147 \\
\hline \multicolumn{2}{c}{ *significant at the 0.05 level } \\
\hline
\end{tabular}

*significant at the 0.05 level

Table 1: Mean Data for Questionnaire Results: AMS-C28, academic locus of control scale and Rosenberg's self-esteem scale

\section{Qualitative data}

\begin{tabular}{l|l}
\hline \hline Primary theme & Secondary theme \\
\hline \hline 1. PBL & Knowledge \\
& Other learning methods \\
& Attitude \\
& Skills \\
& Barriers \\
& Benefits \\
& Feedback \\
\hline 2. Didactic learning methods & Knowledge \\
& Skills \\
& Barriers \\
& Feedback \\
\hline 3. Learning styles & Preferred \\
& PBL \\
& Traditional didactic \\
\hline 4. Feedback & Preference \\
\hline 5. Learner autonomy & Knowledge \\
& Benefits \\
& Barriers \\
& Attitude \\
\hline
\end{tabular}

Table 2: Hierarchy of Themes from Student Focus Groups

At the outset of the module, while many students felt positive about undertaking PBL, they looked for reassurance in terms of tutor guidance and support: "I am unsure about this module as we have never done anything like it before" (pre-G1); "Yes, alright, as far as I understand it there will be guidance along the way as we need a framework" (pre-G1).

Benefits of PBL were perceived to be self-development skills: for example, increased selfconfidence, motivation and greater external benefits in terms of improved grades. Students noted that "it is good for self-confidence" (post-G4) and "increased greater interest in subject and self-confidence generally" (post-G1).

A majority of participants felt that PBL involved independent learning and greater ownership and responsibility by the student as well as having real life application: "It's down to yourself, so if you succeed or fail it's down to your own personal thing" (post-G4). 
Perceived limitations of PBL focused on the lack of time: "Time is a big issue" (pre-G2). The hazards of working in groups were also highlighted: "There may be individual learners in the group who do not share ideas - this could be difficult" (pre-G1). Post-intervention students also highlighted problems in terms of there being no right or wrong answers and the risk of going off in the wrong direction and therefore wasting time: "When we returned and reported it back, it was like, well no that's not what we really want. I just think it was a bit of a waste of time really" (post-G3).

Prior to the intervention participants believed that feedback would be more prevalent using a PBL approach: "You won't be getting feedback from the tutor but from the group" (pre-G3). However, post-evaluation perceptions showed little difference in feedback across the different learning methods: "It's not been any different really" (post-G1), and the preferred method for feedback remained one-to-one with a tutor. Although the learner autonomy concept stressed learning on one's own without aid and PBL emphasised a more groupcentred approach with some guidance, students clearly saw a parallel between PBL and autonomous learning in relation to the independent nature of the work undertaken.

Students' perception of ownership of their learning prior to the PBL intervention was that the tutor would be in control of their learning, as "they [the tutors] are giving you the problem and they control the areas that you choose" (pre-G1). Indeed, one student illustrated the distinct lack of ownership in learning by saying, "We are the little people; we just sit and listen" (preG3). However, after the PBL, students reported that "ownership is with us" (post-G1), and that tutor control was reduced "5\% not 100\%" (post-G1).

The PBL experience created a preference for more groupwork with a practical focus on reallife issues, allowing more student engagement in the process. The key skills to be derived from PBL were employer-related personable skills such as communication, teamwork, motivation and time-management, which, according to one student, "are vital really for work situations" (pre-G4). Post-PBL, one student reiterated: "I think working as a group is like working with colleagues - you come across different people's strengths and weaknesses" (post-G4). These views contrasted with participants' perception of skills derived from more traditional teaching methods, namely note-taking, concentration and coping strategies: "concentration skills for long periods of time" (pre-G4); and "not falling asleep, putting ideas down on paper" (pre-G1).

\section{Discussion}

The primary aim of the study was to investigate whether the use of PBL would promote student autonomy as measured by the assessment of three psychological constructs. A secondary aim was to investigate student perceptions regarding the opportunities to develop employability skills through this PBL approach.

\section{Motivation}

The results suggested that extrinsic motivation appears to be unaffected by the PBL intervention. Extrinsic motivation among the participants was consistently high, especially in comparison to the intrinsic motivation scores. High extrinsic motivation indicates that the students were outcome-oriented. One explanation for this may be in the timing of the study as all grades at this stage contributed to the overall degree classification. Lyddy (1998) and Cassidy and Eachus (2000) support this by suggesting that, in later education, there is an increased emphasis on performance rather than learning. In an incremental ability conception, an individual believes that by increasing their effort they are more likely to achieve. However, to maintain this persistent effort, especially in the face of difficulties and challenges, the individual is more likely to focus on extrinsic factors (Li, 2006). This is particularly true in an academic environment where performance is consistently measured through achievement of specific grades and classifications. The qualitative data reinforce this point as most participants admitted that they were studying in order to: "increase career prospects" (post-G4); "X said it was a chance to get a good grade" (pre-G1). 
Intrinsic motivation was low in the sport and exercise science students primarily because extrinsic motivation was high and perceived as more important in gaining suitable employment opportunities. However, there was a significant increase $(P<0.05)$ in the intrinsic motivation subscale 'to know' following the PBL intervention. This suggests that completing a 12-week PBL course enhanced students' desire to know. Although intrinsic motivation 'to accomplish' and 'to achieve stimulation' also increased by a greater amount than changes in extrinsic motivation, these results were not significant $(P>0.05)$. Overall, there is an indication of a possible emerging trend towards increased levels of intrinsic motivation following a short PBL intervention (12-weeks). This is supported by Dolmans and Schmidt (1994), who found that PBL serves as a powerful stimulus for intrinsic motivation to learn. This shift in intrinsic motivation to learn may occur as a consequence of working in teams, which students perceived as one of the greatest benefits of PBL: "You can come back and get a wider knowledge because more people have gone and done the research" (post-G3). Alternatively, the increase in intrinsic motivation may occur as a result of increased ownership of learning (see 'Locus of control' below), which has also been reported previously (Duncan et al., 2007).

\section{Locus of control}

As might be expected, the locus of control (LOC) amongst the participants prior to the PBL intervention was high, indicating a reliance on powerful, significant others for their own success or failure and a trend towards external LOC.

There was a small but insignificant decrease in the LOC scores after the PBL intervention $(P>0.05)$. However, the qualitative data suggest that participants' perception of control changed more considerably. Prior to the intervention students indicated that ownership of the curricula was with the tutor as "they are giving you the problem and they control the areas that you choose" (pre-G1). On the other hand, after the intervention the consensus was that "ownership is with us" (post-G1). Kremer-Hayon and Tillema, (1999) suggest that selfregulated learners attribute success or failure to themselves rather than others. Similarly, Pajares and Valiante (2002) reported that higher levels of learner autonomy are seen in those students who judge their capability to accomplish tasks as high. The key processes in the PBL approach - identifying own learning issues (needs) and (setting) objectives; conducting independent information gathering and evaluation; and improving the sharing of their results - are likely to contribute to a shift in control (Chung and Chow, 2004). The constructs of the course create a virtuous circle: by increasing the degree of learner control, there is a necessary increase in self-confidence and intrinsic motivation (Dickinson, 1987). The converse is also true, in that students who feel that they are not in control are likely to have decreased confidence in their abilities and decreased self-esteem (Seifert, 2004).

LOC data suggest that the final year sport and exercise science students in this study perceived themselves to have little control over their own success and failure. This finding contradicts that of Fazey and Fazey (2001) who reported that first year undergraduates perceive themselves to be in control of their own success and failure. Pajares and Valiante (2002), Lyddy (1998) and Cassidy and Eachus (2000) all support the existence of a general trend where students show a decrease in confidence in their self-regulatory learning strategies over time.

\section{Self-esteem}

Students' belief in their academic capabilities is known to be highly influential on their motivation to achieve. Indeed, self-efficacy has been shown to have a greater influencing capacity than outcome expectancies (Zimmerman, 2000). In the present study, therefore, with the high self-esteem scores pre- and post-intervention, we would expect to see scores relating to high levels of intrinsic motivation and an internal locus of control. However, this was not the case. It should be noted that sporting populations are likely to have higher selfesteem scores than the normal population (Bailey, 2006). This could be due to the realistic appraisal of skill competency within the sports environment. This often leads to a goal-setting approach where improvements, monitored regularly, contribute to increased feelings of selfefficacy. This is likely to be the main explanation for the high scores recorded, particularly as 
Rosenberg's self-esteem scale questionnaire measures self-esteem as a global construct in which sport is only one part of the hierarchy, thus reflecting the student as a 'person' rather than as a 'learner'. A further possible explanation is that, owing to the timing of the intervention, those students who perceived themselves to be successful in their studies may well have a high level of self-esteem regardless of being extrinsically motivated. A more specific measure to capture aspects of self-esteem might have been preferable - for example, a self-efficacy measure related to the specific learner context may have provided more reliable data. Self-efficacy is seen as a situational aspect of confidence which, over a period of time, can influence an individual's self-esteem (Buckworth and Dishman, 2002).

Participants found it difficult to work outside their comfort zone of regular feedback from tutors. As one student commented, "Yes, if feedback after each problem is given, you know if you have the right angle" (pre-G1). Despite understanding that feedback would come primarily from their group - "wouldn't be getting feedback from the tutor but from the group" (pre-G3) and "we will gain personal feedback from each other when we work as a group" (pre-G4) - participants still demonstrated a high external LOC by their reliance on the feedback from powerful and significant others and placing little relevance on the feedback they received from each other. This again seems contradictory when related to the high selfesteem scores reported in this study. The general nature of the self-esteem scale questions may have inadvertently contributed to this discrepancy through misinterpretation or misapplication of the question content.

\section{Employability skills}

The focus group research indicated that PBL more effectively equipped students with employer-related skills such as teamworking and communication, which, according to one student, "are vital really for work situations" (pre-G4). Post-PBL, one student reiterated: "I think working as a group; it's like working at work with colleagues you come across different peoples strengths and weaknesses" (post-G4). Research has demonstrated that there is a shift towards process-oriented learning that will develop content knowledge, and that employer skills should also be considered (Miliszewska and Tan, 2004; Glover et al., 2002; Little, 2001). PBL does offer more to students than content knowledge through the development of a range of lifelong competencies including critical reasoning, teamwork and problem-solving skills (Major and Palmer, 2001; Chung and Chow, 2004; Dunlop, 2005).

\section{Conclusion}

The present study provided evidence that a comparatively short course of PBL can help promote learner autonomy as measured by a significant increase in levels of intrinsic motivation and non-significant shifts towards an internal locus of control and increased selfesteem. It is likely that a more prolonged use of PBL would generate higher levels of learner autonomy (Dolmans and Schmidt, 1994). Furthermore, students were able to identify that PBL enabled them to develop employability skills in addition to the application of content knowledge.

PBL appears to be an effective learning and teaching strategy for sport and exercise science students in higher education, leading to the development of learner autonomy, content knowledge and employability skills. Sport and exercise science programmes should consider the use of PBL approaches at all levels to encourage development of lifelong learning skills, while taking into account the perceived barriers of time-management, groupwork and effective tutor support and facilitation. Practitioners may also wish to consider whether the apparent use of traditional pedagogic learning styles is reducing students' ability to become autonomous by focusing on outcome rather than process.

\section{References}

Albanese, M.A. and Mitchell, S. (1993) Problem-based learning: a review of literature on its outcomes and implementation issues. Academic Medicine, 68(1), 52-81.

Bailey, R. (2006) Physical Education and Sport in Schools: A Review of Benefits and Outcomes. Journal of School Health, 76(8), 397-401. doi:10.1111/j.1746-1561.2006.00132.x 
Bertrand, J.T., Brown, J. and Ward, V.M. (1992) Techniques for Analyzing Focus Group Data. Education Review, 16(2), 198-209. doi:10.1177/0193841X9201600206

Buckworth, J. and Dishman, R.K. (2002) Exercise Psychology. Champaign, IL: Human Kinetics.

Cassidy, S. and Eachus, P. (2000) Learning Style, Academic Belief Systems, Self-Report Student Proficiency and Academic Achievement in Higher Education. Educational Psychology, 20(3), 307322. doi:10.1080/713663740

Chan, V. (2001a) Learning Autonomously: the learners' perspectives. Journal of Further and Higher Education, 25(3), 285-300. doi:10.1080/03098770120077649

Chan, V. (2001b) Readiness for Learner Autonomy: what do our learners tell us? Teaching in Higher Education, 6(4), 505-518. doi:10.1080/13562510120078045

Chaput de Saintonge, D.M. and Dunn, D.M. (1998) The Helpless Learner: a pilot study in clinical students. Medical Teacher, 20(6), 583-586. doi:10.1080/01421599880337

Chin, C. and Chia, L-G. (2004) Implementing Project Work in Biology through Problem-Based Learning. Journal of Biological Education, 38(2), 69-75.

Chung, J.C.C. and Chow, S.M.K. (2004) Promoting Student Learning through a Student-Centred Problem-Based Learning Subject Curriculum. Innovations in Education and Teaching International, 41(2), 157-167. doi:10.1080/1470329042000208684

Clifford, V.A. (1999) The Development of Autonomous Learners in a University Setting. Higher Education Research and Development, 18(1), 115-128. doi:10.1080/0729436990180109

Cockrell, K.S., Caplow, J.A. and Donaldson, J.F. (2000) A Context for Learning: collaborative groups in the problem-based learning environment. The Review of Higher Education, 23(3), 347-363.

Cokley, K.O. (2000) Examining the Validity of the Academic Motivation Scale by Comparing Scale Construction to Self-Determination Theory. Psychological Reports, 86(2), 560-564. doi:10.2466/PR0.86.2.560-564

Cross, K.P. (1999) Learning is about Making Connections: The Cross Papers, No. 3. Mission Viejio, CA: League for Innovation in the Community College and Educational Testing Service.

Dahlgren, M. and Dahlgren, L. (2002) Portraits of PBL: students' experiences of the characteristics of problem-based learning in physiotherapy, computer engineering and psychology. Instructional Science, 30(2), 111-127. doi:10.1023/A:1014819418051

Daum, T.L. and Wiebe, G. (2003) Locus of Control, Personal Meaning and Self-Concept Before and After an Academic Critical Incident. Masters Thesis, Trinity Western University. Available from: http://66.102.1.104/scholar?hl=en\&lr=\&q=cache:clLOTWfMJiMJ:www.twu.ca/cpsy/PDF/Theses/Da um\%2520Wiebe\%2520Thesis.pdf+Daum+and+Wiebe

Dickinson, L. (1987) Self-Instruction in Language Learning. Cambridge, UK: Cambridge University Press.

Dochy, F., Segers, M., van den Bossche, P. and Gijbels, D. (2003) Effects of problem-based learning: a meta-analysis. Learning and Instruction, 13(5), 533-568. doi:10.1016/S0959-4752(02)00025-7

Dolmans, D.H. and Schmidt, H.G. (1994) What drives the student in problem-based learning? Medical Education, 28, 372-380.

Dolmans, D.H.J.M., Snellen-Balendong, H., Wolfhagen, I.H.A.P. and van der Vleuten, C.P.M. (1997) Seven Principles of Effective Course Design for a Problem Based Curriculum. Medical Teacher, 19(3), 185-189. doi:10.3109/01421599709019379

Duncan, M.J. and Al-Nakeeb, Y. (2006) Using Problem Based Learning in Sports Related Courses: an overview of module development and student responses in an undergraduate sports studies module. Journal of Hospitality, Leisure, Sport and Tourism Education, 5(1), 50-57. Available from: http://www.heacademy.ac.uk/johlste

Duncan, M., Lyons, M. and Al-Nakeeb, Y. (2007) 'You have to do it rather than being in a class and just listening.' The Impact of Problem-Based Learning on the Student Experience in Sports and Exercise Biomechanics. Journal of Hospitality, Leisure, Sport and Tourism Education, 6(1), 71-80. Available from: http://www.heacademy.ac.uk/johlste

Dunlop, J.C. (2005) Problem-based learning and self-efficacy: How a capstone course prepares students for a profession. Educational Technology Research and Development, 53(1), 65-83. doi:10.1007/BF02504858

Fazey, D.M.A. and Fazey, J.A. (2001) The Potential for Autonomy in Learning: perceptions of competence, motivation and locus of control in first year undergraduate students. Studies in Higher Education, 26(3), 345-361. doi:10.1080/03075070120076309

Glover, D., Law, S. and Youngman, A. (2002) Graduateness and Employability: student perceptions of the personal outcomes of university education. Research in Post-Compulsory Education, 7(3), 293306. doi:10.1080/13596740200200132

Heliker, D. (1994) Meeting the challenge of the curriculum revolution: problem-based learning in nursing education. Journal of Nursing Education, 33(1), 45-47.

Holmes, L. (2001) Reconsidering Graduate Employability: the 'graduate identity' approach. Quality in Higher Education, 7(2), 111-119. doi:10.1080/13538320120060006

Kremer-Hayon, L. and Tillema, H.H. (1999) Self-regulated learning in the context of teacher education. Teaching and Teacher Education, 15(5), 507-522. doi:10.1016/S0742-051X(99)00008-6 
Li, W. (2006) Understanding the Meaning of Effort in Learning a Motor Skill: ability conceptions. Journal of Teaching in Physical Education, 25(3), 298-309.

Little, B. (2001) Reading Between the Lines of Graduate Employment. Quality in Higher Education, 7(2), 121-129. doi:10.1080/13538320120060015

Lyddy, F. (1998) It's Not What You Do: what is the link between academic success and learning style? The Psychologist, 11(11), 545.

Major, C.H and Palmer, B (2001) Assessing the Effectiveness of Problem-Based Learning in Higher Education: lessons from the literature. Academic Exchange Quarterly, 5(1), 4-9. Available from: http://www.rapidintellect.com/AEQweb/mop4spr01.htm

Mennin, S., Gordan, P., Majoor, G. and Al Shazali Osman, H. (2003) Position Paper on ProblemBased Learning. Education for Health, 16(1), 98-113. doi:10.1080/1357628031000066633

Mierson, S. and Freiert, K. (2004) Problem-Based Learning. Training and Development, 58(10), 15-17.

Miliszewska, I. and Tan, G. (2004) Realising core graduate attributes in Computer Science through a CPR (Collaboration-Participation-Relevance) approach to teaching. Refereed paper from $27^{\text {th }}$ Annual HERDSA conference, 4-7 July 2004, Miri, Sarawak, AUS. Available from: http://www.herdsa.org.au/wp-content/uploads/conference/2004/PDF/P006-jt.pdf

Miller, C.K. and Peterson, R.L. (2003) Cooperative Learning. 2nd edition. Safe and Responsive Schools, USA: University of Indiana. Available from: http://www.indiana.edu/ safeschl/cooperative learning.pdf

Morgan, D.L. and Krueger, R.A. (1998) The Focus Group Kit. London: Sage.

Morrison, J. (2004) Where Now for Problem-Based Learning? The Lancet, 363(9403), 10 January 2004, 174. doi:10.1016/S0140-6736(03)15298-1

Murphy, H. and Roopchand, N. (2003) Intrinsic Motivation and Self-Esteem in Traditional and Mature Students at a Post-1992 University in the North-East of England. Educational Studies, 29(2/3), 243259. doi:10.1080/03055690303278

Newman, M (2003) A pilot systematic review and meta-analysis on the effectiveness of problem based learning. Newcastle: LTSN centre for Medicine, Dentistry and Veterinary Medicine. Available from: http://www.Itsn-01.ac.uk/resources/features/pbl

O'Neil, P. (2003) Development of Problem-Based Learning (PBL) following Implementation. LTSN Generic Centre, York, May, 109-134. Available from: http://www.heacademy.ac.uk

Pajares, F. and Valiante, G. (2002) Students' Self-Efficacy in their Self-Regulated Learning strategies: a developmental perspective. Psychologia, 45(4), 211-221. doi:10.2117/psysoc.2002.211

Patton, M.Q. (2002) Qualitative Evaluation and Research Methods. 3rd edition. Thousand Oaks, CA: Sage Publications.

Pierson, H. (1996) Learner Culture and Learner Autonomy in Hong Kong Chinese Context. In: R. Pemberton, E. Li, W. Or and H.D. Puson (eds.) Taking Control: Autonomy in Language Learning. Hong Kong: Hong Kong University Press.

Rosenberg, M. (1989) Society and the Adolescent Self-Image (revised edition). Middletown, CT: Wesleyan University Press. Available from: http://www.bsos.umd.edu/socyl

Seifert, T.L. (2004) Understanding student motivation. Educational Research, 46(2), 137-149. doi:10.1080/0013188042000222421

Spronken-Smith, R. (2005) Implementing a Problem-Based Learning Approach for Teaching Research Methods in Geography. Journal of Geography in Higher Education, 29(2), 203-221. doi:10.1080/03098260500130403

Strauss, E.S. and Corbin, J. (1990) Basics of Qualitative Research: Grounded Theory, Procedures and Techniques. London: Sage.

Thomas, C.R. and Gadbois, S.A. (2007) Academic self-handicapping: The role of self-concept clarity and students' learning strategies. British Journal of Educational Psychology, 77(1), 101-119. doi:10.1348/000709905X79644

Trice, A.D. (1985) An Academic Locus of Control Scale for College Students. Perceptual and Motor Skills, 61(3), 1043-1046. Available from: http://www.ccsu.edu/learnctr/ [Accessed 5 July 2005].

Vallerand, R.J., Pelletier, L.G., Blaise, M.R., Briere, N.M., Senecal, C. and Vallieres, E.F. (1992) The Academic Motivation Scale: A Measure of Intrinsic, Extrinsic, and Amotivation in Education. Educational and Psychological Measurement, 52(4), 1003-1017. doi:10.1177/0013164492052004025

Vansteenkiste, M., Lens, W. and Deci, E.L. (2006) Intrinsic Versus Extrinsic Goal Contents in SelfDetermination Theory: Another Look at the Quality of Academic Motivation. Educational Psychologist, 41(1), 19-31. doi:10.1207/s15326985ep4101 4

White, M., Michaud, G., Pachev, G., Lirenman, D., Kolenc, A. and Fitzgerald, J.M. (2004) Randomized Trial of Problem-Based versus Didactic Seminars for Disseminating Evidence-Based Guidelines on Asthma Management to Primary Care Physicians. The Journal of Continuing Education in the Health Professions, 24(4), 237-247. doi:10.1002/chp.1340240407

Yeung, E., Au-Yeung, S., Chiu, T., Mok, N. and Lai, P. (2003) Problem design in problem-based learning: evaluating students' learning and self-directed learning practice. Innovations in Education and Teaching International, 40(3), 237-244. doi:10.1080/1470329032000103762 
Martin, West and Bill (2008) Incorporating Problem-Based Learning Strategies to Develop Learner Autonomy and Employability Skills in Sports Science Undergraduates

Zimmerman, B.J. (2000) Self-Efficacy: An Essential Motive to Learn. Contemporary Educational Psychology, 25(1), 82-91. doi:10.1006/ceps.1999.1016 


\section{Appendix}

\section{SPOR3018 SPORT \& EXERCISE SCIENCE IN PRACTICE SCENARIO 3: ATHLETE SUPPORT}

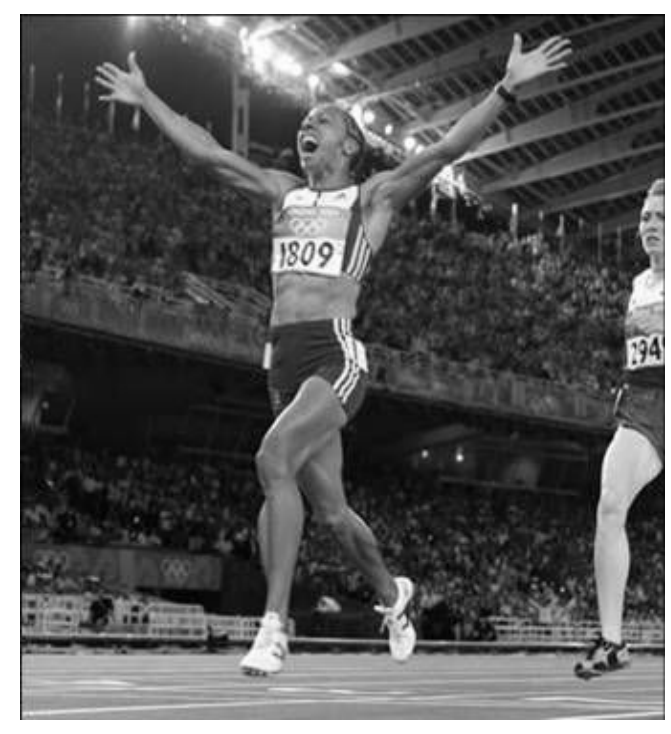

\section{CHAMPION HOLMES}

At 34 , and the oldest woman in the field, Kelly Holmes, after a career dogged by injuries and disappointments, won the 800 metres and 1500 metres Olympic gold medals in Athens, a feat only ever achieved by two women before. Holmes is the only athlete ever to reach the 800 metres and 1500 metres finals three times.

Holmes has suffered an agonising series of nearmisses in her career. She was squeezed out of the medals with fourth place in the 800 metres at the 1996 Atlanta Olympics after suffering a stress fracture. Injury also ruined her bid for the 1997 World Championship 1500 metres and many

HOLMES KEEPS ON RUNNING

"I don't plan to retire. I'm in the best shape of my life. I would still like to win an Indoors title but I have aot mv dream twice over"

Saturday $29^{\text {th }}$ August 2004

\section{HOLMES CASTS DOUBT ON WORLDS BID}

Holmes said she has "no ambition" to compete in Helsinki in August. "Will I have as much commitment, desire and energy to go through a major, major champs like that? This is what I don't know... I gave absolutely everything to the Olympics and that is why I found it hard to get back into training." Saturday $29^{\text {th }}$ January 2005

What issues/problems will this successful athlete need to address in order to have continued success in the athletic arena?

Indicate appropriate sports science support strategies that could be integrated into her programme to ensure further success.

Photograph and Quotes from:

Photograph: http://news.bbc.co.uk/sport1/hi/olympics 2004/photo galleries/3592840.stm "Holmes Keeps on Running": http://news.bbc.co.uk/sport1/hi/olympics 2004/athletics/3609426.stm "Holmes Casts Doubt on Worlds Bid": http://news.bbc.co.uk/sport1/hi/athletics/4219517.stm 